\title{
Cutaneous Metastasis of Gastric Carcinoma: A Rare Case with Unusual Presentation Site
}

\author{
Yomna Dannouni $^{1 *}$, Sara Boulajaad ${ }^{1}$, Adil Ait Errami ${ }^{1}$, Zouhour Samlani $^{1}$, Sofia Oubaha ${ }^{2}$, Khadija Krati ${ }^{1}$
}

${ }^{1}$ Department of Gastroenterology, Mohamed VI University Hospital, Marrakech, Morocco

${ }^{2}$ Laboratory of Physiology, Cadi Ayyad University Faculty of Medicine and Pharmacy of Marrakech, Morroco

DOI: $10.36347 /$ simcr.2020.v08i05.016

| Received: 06.02.2020 | Accepted: 13.02.2020 | Published: 23.05.2020

*Corresponding author: Yomna Dannouni

\section{Abstract}

Gastric linitis is a very specific form of gastric adenocarcinoma. Its diagnosis is based on morphological arguments of an infiltrating tumour in the stomach with an histology: characteristic stroma reaction of the tissue is especially apparent in the submucosa, although it can also be noted in the muscle layer and subserosa. In most typical cases, the cells appear in a signet-ring form. Cutaneous metastases from gastric cancer are very rare. The incidence of cutaneous metastases of the upper digestive tract carcinomas and of all gastric cancer is respectively less than $1 \%$ and $0.8 \%$. We report the case of gastric linitis with Cutaneous metastases. This metastatic site is often associated with advanced tumor stage and worse prognosis.

Keywords: Gastric linitis, infiltrating tumour, histology, subserosa.

Copyright @ 2020: This is an open-access article distributed under the terms of the Creative Commons Attribution license which permits unrestricted use, distribution, and reproduction in any medium for non-commercial use (NonCommercial, or CC-BY-NC) provided the original author and source are credited.

\section{INTRODUCTION}

Skin represents a common site for metastases from melanoma, lung, breast and colon cancers [1, 2]. They can be revealing and allow the diagnosis of the primary tumour. Cutaneous metastases of gastrointestinal tumours are rare and represent less than $4 \%$ [1]. The occurrence of skin metastases of gastric adenocarcinomas is an extremely rare situation, but it must be known as it may precede gastric symptomatology and be, on its own, indicative of neoplasia. The prognosis of the disease at the skin metastasis stage is usually poor. In this observation, we report the case of a 59-year-old patient with gastric linitis with cutaneous, peritoneal and gonglionary metastases.

\section{OBSERVATION}

Mr. M. Z., 59 years old, a chronic smoker for 9 packets/year, who has been reporting for 7 months atypical epigastralgia with appearance of nodules in the chest and scalp, without any other associated signs, in a context of alteration of the general state and weight loss of $8 \mathrm{~kg}$. Physical examination revealed a dehydrated patient with a body mass index of $17 \mathrm{~kg} / \mathrm{m}^{2}$ and epigastric sensitivity. Dermatological examination revealed 4 red subcutaneous nodules, varying in size between 1 and $4.5 \mathrm{~cm}$, with a firm and painless character located in the thorax and scalp (Images 1-2). The rest of the examination was normal, particularly the pleuropulmonary examination, and the lymph node areas were free. He presented a iron deficiency anemia at $9.5 \mathrm{~g} / \mathrm{dl}$.

An oesogastroduodenal fibroscopy was performed, which revealed a non-stenosing circumferential ulcerous process taking up the whole gastric body. An anatomopathological examination with immunohistochemical complement of the biopsies carried out had concluded to a poorly differentiated adenocarcinoma with anti-pancytokeratin-positive isolated in a signet-ring form cell. Biopsy of the subcutaneous nodule confirmed the cutaneous localization of a poorly differentiated adenocarcinoma with a signer-ring cell contingent. 


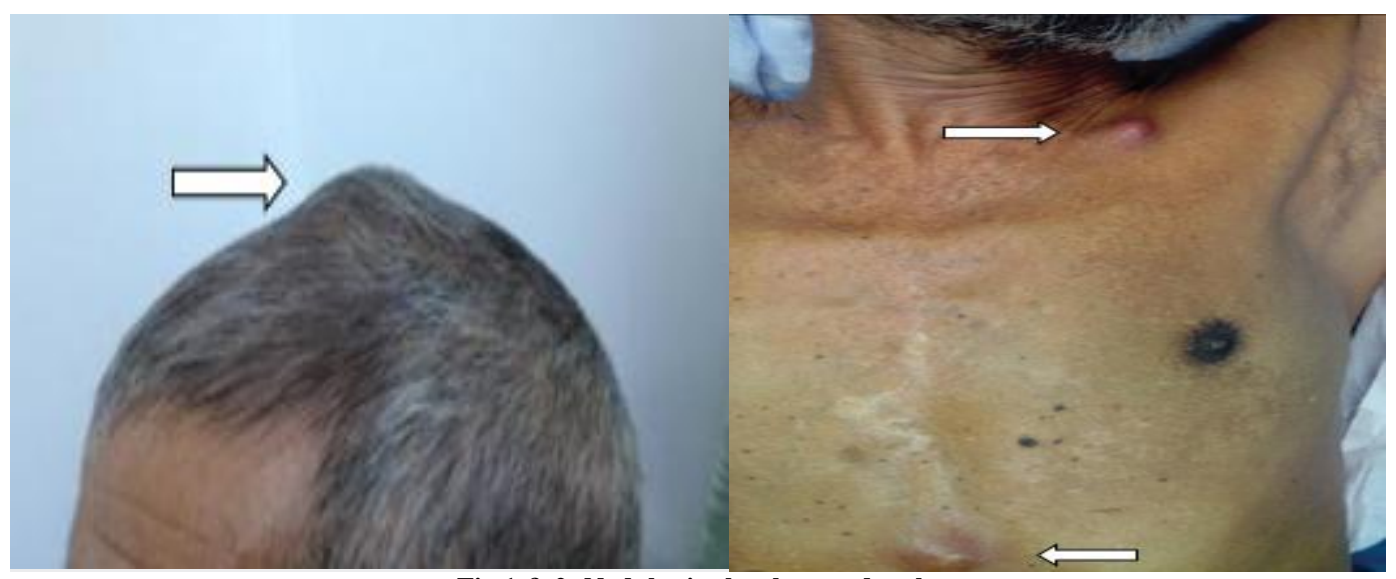

Fig 1 \& 2: Nodules in the chest and scalp

The thoracoabdominal computed tomography (CT) scan revealed an invasion of the stomach, peritoneal carcinomatosis and ascitis (Figure-3). Palliative chemotherapy was indicated in the patient after a prechemotherapy check-up.

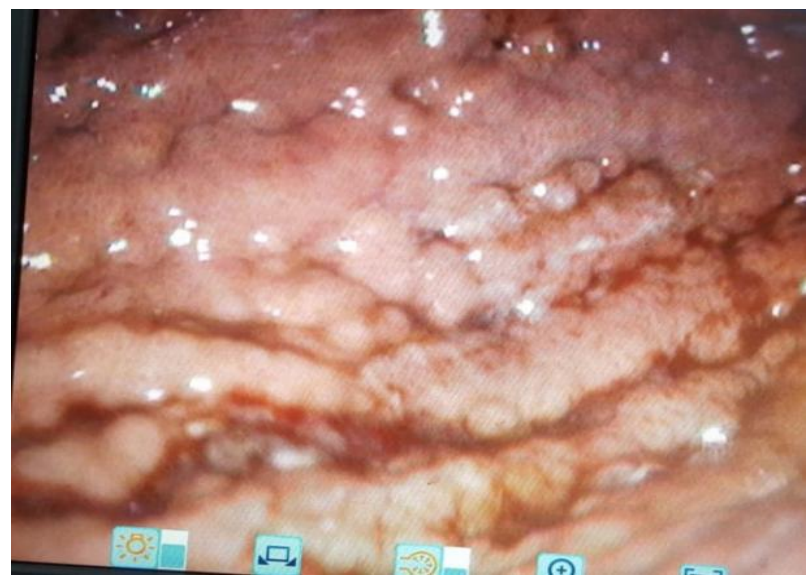

Fig-3: Endoscopy showing thickened gastric folds

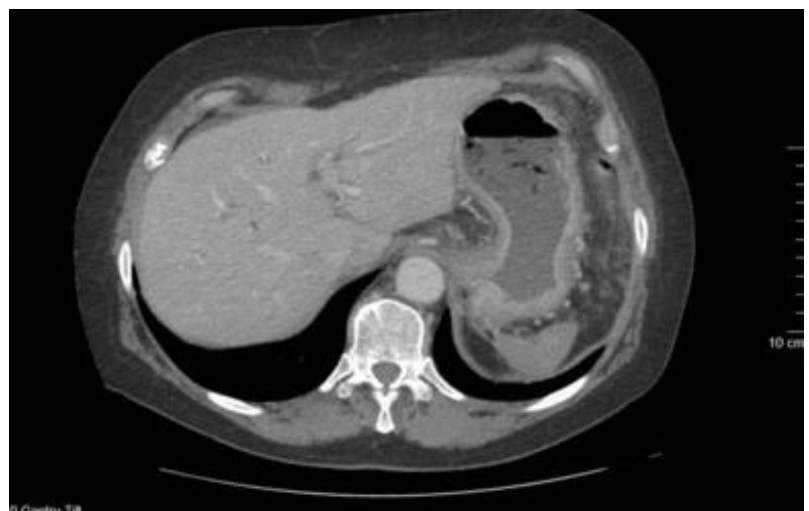

Fig-4: Abdomen scanner showed an infiltration of the gastric wall with peritoneal carcinomatosis ans ascitis

\section{DISCUSSION}

Gastric linitis plastica is a diffuse type of cancer which is characterised by a thickening and rigidity of the stomach wall. It is notorious for its failure to cause early symptoms, and patients with symptoms generally have a more advanced form of the disease. Cutaneous metastases of linitis are very rare.
Only 16 to $20 \%$ of skin metastases are signet ring cell cancers [3]. Any cancer can metastasize into the skin, most often after the discovery of the primary tumor. Sometimes, there is a simultaneity between the occurrence of a skin metastasis and the revelation of its primary neoplasia, which is the case of our patient. Finally, the metastasis may appear isolated, while the primary cancer has not yet been detected [4]. The mechanism of metastatic dissemination is unclear, and is largely via the lymphatic vessels. The clinical presentations of skin metastases are polymorphic, dominated according to the literature by the nodular aspect. Metastatic nodules are generally few in number and may adopt a variable regional grouping depending on the nature of the primary cancer. They are firm and usually painless. They can reach a few centimetres in diameter and appear suddenly. They usually grow rapidly before stabilizing in their expansion, but do not tend to regress spontaneously [2]. The abdomen and chest are the most common sites of skin metastases. Other locations such as the cervical region and the scalp (as the case of our patient) have been reported in the literature [5]. The immunohistochemical characteristics of the lesion are similar to those of the primary tumour. The prognosis of gastric carcinomas with cutaneous metastases is poor due to neoplastic dissemination, with high mortality, mean survival of 7.5 months [6].

\section{CONCLUSION}

Gastric linitis or gastric ring cell adenocarcinoma is a cancer with a poor prognosis. Cutaneous metastases of gastric adenocarcinomas are an extremely rare clinical situation, but one that must be known as it may precede gastric symptomatology and be, on its own, indicative of neoplasia. Cutaneous metastasis must always be suspected in the presence of an unexplained skin nodule and knowledge of these rare conditions is the only guarantee of early diagnosis and better management.

\section{REFERENCES}

1. Avgerinou G, Flessas I, Hatziolou E, Zografos G, Nitsios I, Zagouri F, Katsambas A, Kanitakis J. 
Cutaneous metastasis of signet-ring gastric adenocarcinoma to the breast with unusual clinicopathological features. Anticancer research. 2011 Jun 1;31(6):2373-2378.

2. Krathen RA, Orengo IF, Rosen T. Cutaneous metastasis: a meta-analysis of data. South Med Journal, 2003; 96:164-167.

3. Ahn SJ, Oh SH, Chang SE, Jeung YI, Lee MW, Choi JH, Moon KC, Koh JK. Cutaneous metastasis of gastric signet ring cell carcinoma masquerading as allergic contact dermatitis. Journal of the European Academy of Dermatology and Venereology. 2007 Jan;21(1):123-4.
4. Henry F, Pierard C, Arrese Estrada J, Claessens N, Paquet P, Pierard G. Comment j'explore... une métastase orpheline d'un mélanome. Revue Médicale de Liège. 2002;57(6):405-407.

5. Leonard N. Cutaneous metastases: Where do they come from and what can they mimic ? Current Diagnostic Pathology. 2007;13(4):320-330.

6. Ayamperumal A, Tharini G, Ravindran V, Parveen B. Cutaneous manifestations of internal malignancy. Indian Journal Dermatol, 2012; 57(4):260-264 